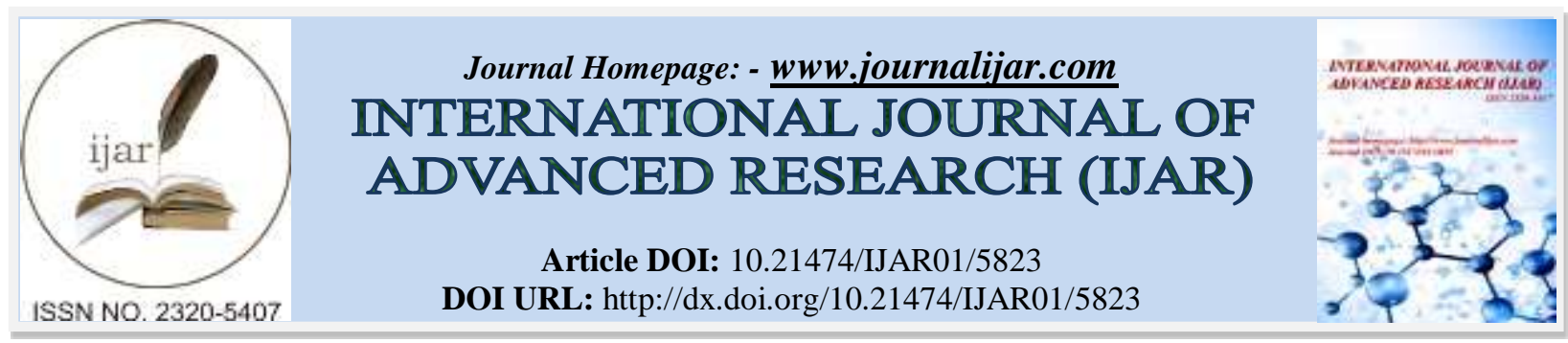

RESEARCH ARTICLE

\title{
APPLYING PROGRAM THEORY AND LOGICAL MODEL TO DESIGN, IMPLEMENT, AND EVALUATE SELF-REGULATED STRATEGY DEVELOPMENT PROGRAM.
}

\author{
Su-ching Lin, Ming-sui Wu and Yu-ying Chu. \\ National Changhua University of Education; Ming-Chuan University; Yun Lin Junior High School, Taiwan.
}

\section{Manuscript Info}

Manuscript History

Received: 10 September 2017

Final Accepted: 12 October 2017

Published: November 2017

Key words:-

program theory, logical model, selfregulated strategy development, writing performance, learning motivation of writing, self-regulated strategy of writing.

\section{Abstract}

This study aimed to apply Self-Regulated Strategy Development (SRSD) theory and logical model to design, implement, and evaluate SRSD program (SRSDP) in order to learn the impacts of SRSDP on junior high school students' self-regulated learning strategy of writing, writing performance, and learning motivation of writing. The participants consisted of 31 seventh graders. The SRSDP had been implemented for 12 weeks. During the research period, the data were collected through teaching journals, worksheets, teacher's observation records, focus group interview, and scales of writing learning motivation, writing self-regulated strategy, and writing performance. This study only reported the findings of quantitative results. Quantitative data analysis included descriptive analysis and $t$-test. The findings of this study confirmed SRSDP had positive influences on students' writing learning including enhancing students' self-regulated learning strategy of writing, writing performance, and learning motivation of writing. Based on the findings, the conclusion and discussion were also made in this study.

Copy Right, IJAR, 2017,. All rights reserved.

\section{Introduction:-}

Writing has been one of focus for Language Art education because the process of writing can cultivate students' various capabilities, including integration, expression, logic, organization, reflection, critical thinking, social cognitions, and appreciation. These capabilities not only contribute to personal daily life and academic performance, but also benefit the development of their careers in the future (Fitzgerald, 2013; Harris \& Graham, 2009). However, due to the complexity and difficulty of writing, many junior high students have negative feelings toward writing, even regard it as boring and stressful. Several studies conducted in Taiwan setting revealed that writing skills ought to be improved in secondary school level (Gao, 2006; Xu \& Yang, 2010; Yang, 2006) such as purposive sampling, structure, organization, spelling, formatting, and punctuation. Many factors might contribute to the poor writing. One of them might be students themselves. According to Harris, Graham, and Adkins (2015), skilled writing is complex, requiring extensive self-regulation of a flexible, goal-directed, problem-solving activity. Knowledge about writing (including genre knowledge) and strategies for planning and text production are also critical (Harris \& Graham, 2009). If students lack background knowledge about writing, interest, meta-cognition, and motivation, it is impossible to have good writing performance; another factor could come from teachers' teaching. If a teacher cannot apply the appropriate teaching model and strategies for writing, it might be impossible to deliver his/her teaching 
effectiveness. Therefore, it is necessary to take account of both teacher and student factors at the same times if we want to improve students' writing performance.

However, earlier writing instruction neglected inquiry of writing psychology so that its effectiveness was limited (Hillocks, 1984). Until the late 1960's and early 1970's writing and research into another orientation, scholars of cognitive psychology addressed information processing model, writers could develop self-regulated ability through peer editing or self-help (Hayes \& Flower, 1983). Flower and Hayes (1981) introduced a theory of the cognitive processes of writing (CPW), which involved in three dimensions, including writing environment, long-term memory, and writing process composing of stages of planning, transcription, and reviewing. However, this model received some critics, Hayes (1996) has proposed the modification of his model. Hayes's revised model comprises major two dimensions, individual and task environment. Hayes has named it "an individual-environmental model". The individual dimension comprises of the writer's cognition, affection, and memory system. The environmental dimension referring to both the writer's social and physical environment. It concerns all the external factors that can influence the writer.

Self-Regulated Learning (SRL) theory presented by Zimmerman (1986) was based on self-regulation. Over the past few decades, SRL has become a prominent area of research in educational psychology. SRL can be defined as learning that results from students' self-generated thoughts and behaviors that are systematically oriented toward the attainment of their learning goals (Schunk, 2001; Zimmerman, 1989). SRL is an active, constructive process whereby learners set goals for their learning and attempt to monitor, regulate, and control their cognition, motivation, and behavior guided and constrained by their goals and contextual features of the environment. In other words, SRL referring to individual cognition, emotion, action, and situational context factors is a self-directed process to transform learning skills, intelligence, and other mental abilities into academic skills (Zimmerman, 2001).

Self-Regulated Strategy Development (SRSD) model of teaching writing influenced by SRL theory and Hayes's model was created by Harris and Graham (1996). This model composes of six stages, including developing background knowledge, discussing it, modeling it, memorizing it, supporting it, and independent performance. Its major goal is helping students to manage their thoughts, behaviors, and emotions in order to successfully navigate their learning experiences. Along with different teaching stages, students literally master the use of self-regulated strategies into their writing task (Campbell \& Campbell, 2009; Nakata, 2010). SRSD model has five critical characteristics. First, writing strategies and self-regulation strategies, as well as declarative, procedural, and conditional knowledge is explicitly taught and supported in developing. Second, students are regarded as active collaborators working with the teacher and each other during instruction. Third, the instruction is individualized so that the processes, skills, and knowledge targeted for instruction are tailored to student's needs and capabilities. Goals are adjusted to current performance for each student, with more capable writers addressing more advanced goals. Fourth, the instruction is criterion-based rather than time-based; students move through the instructional process at their own pace and do not proceed to later stages of instruction until they have met criteria for doing so. Importantly, the instruction does not end until the student can use the strategy and self-regulation procedures efficiently and effectively. Fifth, SRSD is an on-going process in which new strategies are introduced and previously taught strategies are upgraded over time (Graham \& Harris, 2003; Graham, Harris, \& Mason, 2005).

Originally, this model was designed to help the students with writing difficulties and clearly provided the students with problem-solving skills (Harris, Graham, \& Mason, 2006; Mason, Harris, \& Graham, 2011; Santangelo, Haris, \& Graham, 2008). More recently, SRSD model has also effectively applied to the regular students in writing classes across all grade levels to change and improve various aspects of students' performance, including quality of writing, knowledge of writing, approach to writing, and self-efficacy (Bakry \& Alsamadani, 2015; Festas, Oliveira, Rebelo, Damião, Harris, \& Graham, 2015; Graham, McKeown, Kiuhara, \& Harris, 2012; Harris \& Graham, 2009; Harris, Graham, \& Adkins, 2015; Graham, McKeown, Kiuhara \& Harris, 2012; Skibbe, Connor, Morrison, \& Jewkes, 2011). Therefore, this study attempted to apply SRSD model for improving seventh graders' writing in Taiwan.

Program Theory (PT) focuses on assumptions about mechanisms underlying a program or intervention that are believed to realize the goals of an intervention or program (Donaldson \& Leeuw, 2015). Chen and Rossi (1983) indicated that the sequence of lack of attention to PT could result in narrow outcomes or sometimes distorted understandings of programs. Specifically, PT plays a major role to construct plausible and defensible models of how programs can be expected to work and offer a logical framework for program processes, outcomes, measurement, data collection, and evaluations (Chen \& Rossi, 1983). PT can be based on the application of a social science theory 
to a specific program and target population. Major elements of PT could be composed of the following: (a) the problem area, or behavior to be addressed by the program and the target population and context conditions; (b) program content, or skills to be acquired that will be sufficient to produce an effect; and (c) key responses and outcomes of the program by domain. PT may derive from a variety of sources such as previous research findings, social science theory, program designers, or, if necessary, from the evaluator (Donaldson, 2007; Reynolds, 1998). The terms PT and "program logic" are often used interchangeably by evaluators, but there appears to be growing recognition that they actually serve different functions (Chen, 2006). Program logic is often used to identify and describe the way in which a program fits together, usually in a simple sequence of inputs, activities, outputs, and outcomes (Astbury \& Leeuw, 2010). According to Millar, Simeone, and Carnevale (2001), logic models are useful to any person trying to plan, manage, account for, audit, evaluate, or explain the connections between what a program requests in terms of resources and what it seeks to accomplish. Thus, a logic model can act as a tool to guide program design and development at many levels.

Based on the above, in this case study, the authors designed SRSDP based on SRSD's prior theory and previous research and used a logical model as a framework to construct program implementation and evaluations. During the research period, the data were collected through qualitative and quantitative methods. However, this study only reported the findings of quantitative results, including the impacts of SRSDP on seventh graders' self-regulated learning strategy of writing, writing performance, and learning motivation for writing.

\section{Methods:-}

\section{Using a program theory and logical model design:-}

The study developed a conceptual framework as a strategy or tool for operationalizing a program theory. The framework represents the elements of a program theory as concepts or variables and proposes specific relationships among them. The conceptual framework organizes the variables representing the elements of a program theory into five categories: SRSDP theory resources, SRSDP elements, SRSD teaching stages, impact factors, and SRSDP outcomes (shown as Figure 1).

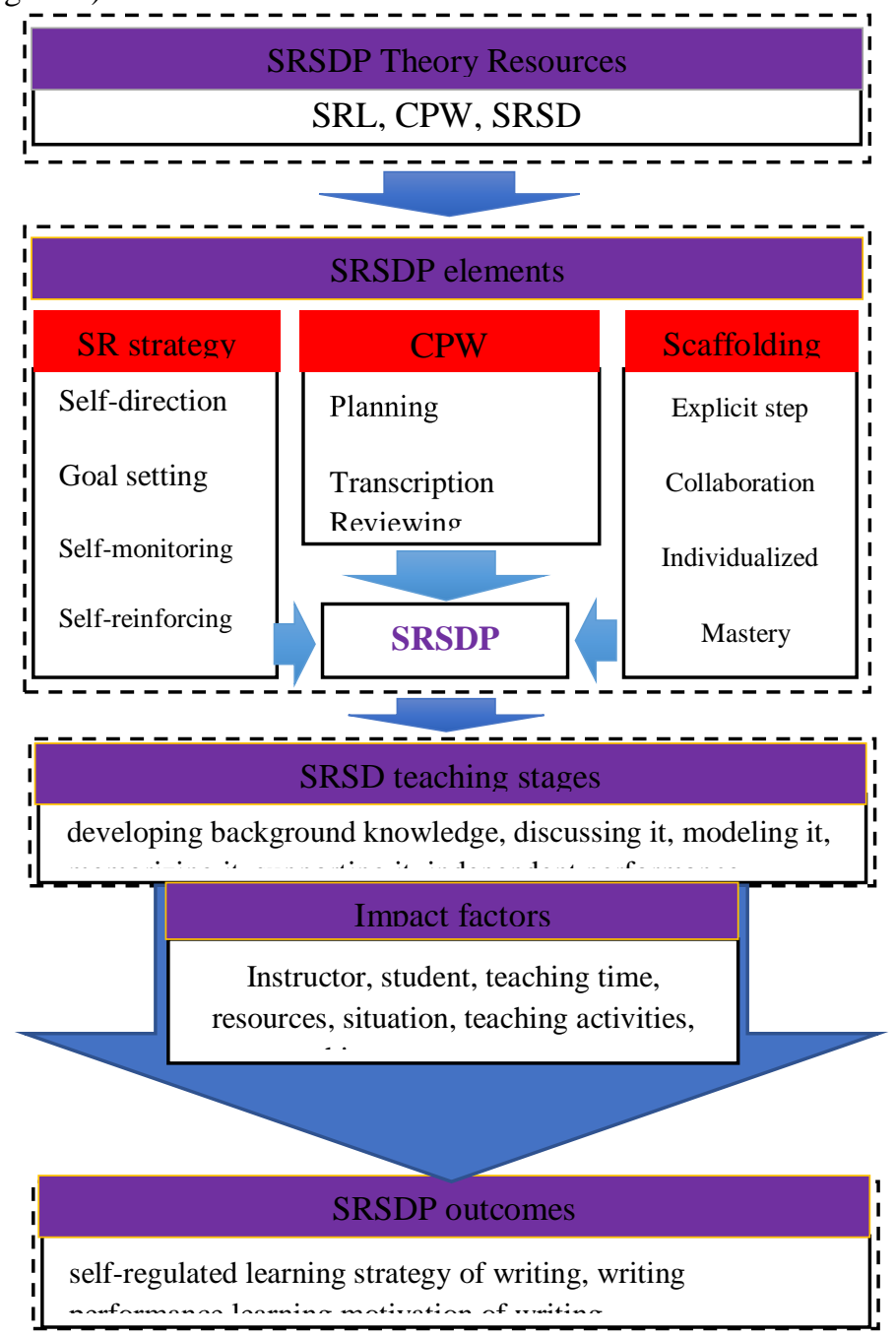




\section{Participants and program implementation:-}

The participants in this study consisted of 31 seventh-graders. Six stages in SRSD teaching model included developing background knowledge, discussing it, modeling it, memorizing it, supporting it, and independent performance. Along with different stages of teaching, the instructor tried to transfer the writing responsibilities to the students. The SRSDP in this study composed of 12-weeks curricular units which covered six stages. First, the instructor introduced the process of writing, through a description of the importance of writing strategies and selfregulated strategies including self-instruction, goal-setting, self-monitoring, and self-reinforcement. Next, the instructor guided students to discuss how to use these strategies. Second, the instructor took an example to demonstrate how to apply self-regulated strategies during the writing processes. Third, through discussion, each group attempted to use self-regulated strategies in completing writing task collaboratively. Fourth, the instructor reviewed and modified group writing respectively, and guided whole class to share their experiences about applying self-regulated strategies into their writing. Fifth, each student independently practiced using self-regulated strategies to his/her own writing. The instructor supported the students' strategy use and provided feedback on writing and self-regulation. The last stage is independent performance. Students used strategies of self-regulation in writing independently. In general, in order to help every student learned successfully, the instructor deeply concerned to provide students' learning scaffolding such as explicit step, collaboration, individualized, mastery, flexibility, developmental, and real-time feedback.

\section{Data collection and analysis:-}

Three major quantitative instruments, Self-Regulated Learning Strategies Scale (SRLSS), Writing Performance Scale (WPS), and Writing Learning Motivation Scale (WLMS) were used in pre-test and post-test to assess the impacts of the SRSDP on students' writing learning. SRLSS developed by Jiang (2013) with 43 items was designed to measure five dimensions, including writing cognition, motivation, emotion, behavior, and situation. Students were asked to rate the items on a four-point Likert scale anchoring at 1,2,3, and 4 (from always to never). The factor analysis revealed that each item in all subscale dimensions produced factor loadings was $67.40 \%$. The overall internal consistency (Cronbach's $\alpha=.91$ ) for the scale was good. The Cronbach's $\alpha$ for the five subscales ranged from .48 to .84 , indicating good internal consistencies of the items within each subscale. WPS developed by the Psychological and Educational Testing Research and Development Center (2013) in National Taiwan Normal University with seven levels from zero to sixth was designed to assess writing skills including purposive sampling, structure and organization, wording and phrasing, and spelling, formatting and punctuation. Inter-rater correction coefficient for the four dimensions ranged $.92, .91, .89$, and .93 . The overall inter-rater correction coefficient (.94) for the scale was good.

WLMS created by Wang (2009) with 26 items were designed to measure four dimensions including interest, selfefficacy, emotion, and importance and utility. Students were asked to rate the items on a four-point Likert scale anchoring at $1,2,3$, and 4 (from strongly disagree to strongly agree). The factor analysis made on data obtained by WLMS revealed that each item in all subscale dimensions produced factor loadings was $61.58 \%$. The overall internal consistency (Cronbach's $\alpha=.91$ ) for the scale was good. The Cronbach's $\alpha$ for the four subscales ranged from .85 to .93 , indicating good internal consistencies of the items within each subscale.

Data analysis was done using SPSS 20.0 for Windows. Results were analyzed using descriptive statistics in terms of mean values, standard deviations, and dependent sampling t-test.

\section{Results:-}

The impact of SRSDP on students' self-regulated learning strategy of writing:-

Table 1 indicated significant differences between pre-test means and post-test means in SRLSS including dimensions of motivation $(t=2.95, p<.01)$, emotion $(t=2.34, p<.05)$, behavior $(t=2.22, p<.05)$, situation $(t=2.45, p$ $<.05)$, and overall $(t=2.67, p<.05)$. Besides, post-test scores significantly higher than pre-test scores. Therefore, this study confirmed that SRSDP provided remarkable positive influences on students using self-regulated learning strategy to their writing.

Table 1:- $t$-test of dimensions of SRLSS $(n=31)$

\begin{tabular}{|l|l|l|l|l|l|}
\hline \multirow{2}{*}{ subscale dimension } & \multicolumn{2}{|l|}{ Pre-test } & \multicolumn{2}{l|}{ Post-test } & \multirow{2}{*}{ t } \\
\cline { 2 - 6 } & $M$ & $S D$ & $M$ & $S D$ & \\
\hline cognition & 2.28 & .58 & 2.53 & .67 & 1.58 \\
\hline
\end{tabular}




\begin{tabular}{|l|l|l|l|l|l|}
\hline motivation & 2.13 & .72 & 2.68 & .72 & $2.95 * *$ \\
\hline emotion & 2.13 & .73 & 2.59 & .70 & $2.34 *$ \\
\hline behavior & 2.10 & .63 & 2.52 & .83 & $2.22 *$ \\
\hline situation & 2.00 & .60 & 2.40 & .82 & $2.45 *$ \\
\hline overall & 2.14 & .42 & 2.53 & .70 & $2.67 *$ \\
\hline
\end{tabular}

$* p<.05 . * * p<.01$

The impact of SRSDP on students' writing performance:-

Table 2 indicated significant differences between pre-test means and post-test means in each dimension of WPS including purposive sampling $(t=4.25, p<.001)$, structure and organization $(t=5.71, p<.001)$, wording and phrasing $(t=4.31, p<.001)$, spelling, formatting, and punctuation $(t=4.79, p<.001)$, and overall $(t=5.04, p<.001)$. Besides, post-test scores significantly higher than pre-test scores. Therefore, this study confirmed that the SRSDP could significantly improve students' writing performance.

Table 2:- $t$-test of dimensions of WPS $(n=31)$

\begin{tabular}{|l|l|l|l|l|l|}
\hline \multirow{2}{*}{ subscale dimension } & Pre-test & Post-test & \multirow{2}{*}{$t$} \\
\cline { 2 - 6 } & $\mathrm{M}$ & $\mathrm{SD}$ & $\mathrm{M}$ & $\mathrm{SD}$ & \\
\hline purposive sampling & 2.77 & 1.20 & 3.29 & 1.10 & $4.25^{* * *}$ \\
\hline structure \& organization & 2.68 & 1.14 & 3.39 & 1.11 & $5.71^{* * *}$ \\
\hline wording \& phrasing & 2.52 & 1.03 & 3.00 & 1.00 & $4.31^{* * *}$ \\
\hline spelling, Format, \& punctuation & 2.52 & .85 & 3.23 & 1.02 & $4.79^{* * *}$ \\
\hline overall & 3.16 & 1.16 & 3.68 & 1.05 & $5.04^{* * *}$ \\
\hline
\end{tabular}

$$
* * * p<.001
$$

The impact of SRSDP on students' learning motivation of writing:-

Table 3 showed significant differences between pre-test means and post-test means in WLMS including dimensions of self-efficacy $(t=2.37, p<.05)$, emotion $(t=2.20, p<.05)$, and importance and utility $(t=2.34, p<.05)$, and overall $(t=2.33, p<.05)$. Besides, post-test scores significantly higher than pre-test scores. Hence, this study confirmed that SRSDP greatly benefits to students' writing self-efficacy and emotion and awareness of writing importance and utility except for writing interest.

Table 3:- $t$-test of dimensions of WLMS $(n=31)$

\begin{tabular}{|l|l|l|l|l|l|}
\hline \multicolumn{2}{|l|}{} & \multicolumn{2}{l|}{ Post-test } & $t$ \\
\hline subscale dimension & Prest & SD & M & SD & \\
\hline interest & 1.88 & .65 & 2.14 & .91 & 1.49 \\
\hline self-efficacy & 1.94 & .45 & 2.33 & .92 & $2.37^{*}$ \\
\hline emotion & 1.99 & .49 & 2.30 & .94 & $2.20^{*}$ \\
\hline importance and utility & 1.89 & .49 & 2.29 & .93 & $2.34^{*}$ \\
\hline overall & 1.93 & .45 & 2.28 & .90 & $2.33^{*}$ \\
\hline
\end{tabular}

$* p<.05$.

\section{Conclusion and discussion:-}

This study aimed to apply SRSD theory and logical model to design, implement, and evaluate SRSDP for junior high school students. The evaluation focused on investigating the impacts of the program on students' self-regulated learning strategy of writing, writing performance, and learning motivation for writing. Three findings were found in this study.

First, SRSDP provided significant positive influences students' self-regulated learning strategies of writing such as cognition, motivation, emotion, behavior, and situation. This finding resembles that of Jiang (2013) in that SRSD helped students to increase self-regulated strategies of writing. One of the reasons is probably because SRSD is an on-going process in which new strategies previously are taught and are upgraded over time insists that the instruction does not end until the student can use the strategy and self-regulation procedures efficiently and effectively, which could be considered the major reason to increase students' mastery of applying self-regulated strategies in this case study. 
Second, SRSDP provided remarkable positive influences on overall students' writing performance, such as purposive sampling, structure and organization, wording and phrasing, spelling, formatting, and punctuation. This finding resembles that of previous studies (Graham, McKeown, Kiuhara \& Harris, 2012; Harris, Graham, \& Adkins, 2015; Harris \& Graham, 2009; Skibbe, Connor, Morrison, \& Jewkes, 2011) to some extent also support claims of Zimmerman (1998), in that SRL is an active and self-directed process. The writers can covert cognition, emotion, action, and situational context factors into academic skills. SRSDP in this case study taught students to use selfregulated strategies focusing on self-direction, goal setting, self-monitoring, and self-reinforcement, which is believed to be capable of improving writing performance for students. Besides, Learning scaffolding was provided for students such as explicit step, collaboration, individualized, mastery, flexibility, developmental, and real-time feedback during teaching processes, which could be contributed to improving students' writing performance.

Third, SRSDP made significant positive influences on overall students' learning motivation of writing such as writing self-efficacy, writing emotions, and importance and utility of writing in this case study. This finding is similar to that of Graham, McKeown, Kiuhara \& Harris (2012) and Harris and Graham (2009), in that SRSD is believed to be capable of helping students to enhance learning motivation. One of the reasons is probably because SRSD views learner as active collaborators. Instruction is tailored to students' needs and capabilities. Goals are adjusted to current performance for each student, students move through the instructional process at their own pace. These characteristics of SRSD teaching procedures could be contributed to enhancing students' learning motivation of writing.

To sum up, students improved their writing performance, learning motivation of writing, and self-regulation strategy of writing after SRSDP in this case study because SRSD teaching model stressed planning, feedback, revising, goal setting, self-instruction, and self-monitoring, and self-reinforcement, and was tailored to students' needs, capabilities and learning pace.

\section{Acknowledgement:-}

The authors would like to thank the Ministry of Science and Technology, Taiwan for financially supporting this research under Contract No. MOST 106-2918-I-018 -002.

\section{References:-}

1. Astbury, B., \& Leeuw, F. L. (2010). Unpacking black boxes: Mechanisms and theory building in evaluation, American journal of evaluation, 31(3), 363-381.

2. Bakry, M. S., \& Alsamadani, H. A. (2015). Improving the persuasive essay writing of students of Arabic as a foreign language (AFL): Effects of Self-Regulated Strategy Development. Procedia - Social and Behavioral Sciences, 182, 89-97.

3. Bandura, A. (1986). Social foundations of thought and action: A social cognitive theory. Englewood Cliffs, NJ: Prentice-Hall.

4. Brandt, D. (1992). The cognitive as the social--An ethnomethodological approach to writing process research. Written Communication, 9 (3), 315-351.

5. Campbell, W. K., \& Campbell S. M. (2009). On the self-regulatory dynamics created by the peculiar benefits and costs of Narcissism: A contextual reinforcement model and examination of leadership. Self and Identity, 8, 214-232.

6. Chen, H. T. (2006). A theory-driven evaluation perspective on mixed methods research. Research in the Schools, 13(1), 75-83.

7. Chen, H. T., \& Rossi, P. H. (1983). Evaluating with sense: The theory-driven approach. Evaluation Review, 7, 283-302.

8. Donaldson, S. I. (2007). Program theory-driven evaluation science. New York, NY: Lawrence Erlbaum.

9. Donaldson, S. I., \& Leeuw, F. L. (2015). Theory in evaluation: Reducing confusion and encouraging debate. Evaluation, 21 (4), 467-480.

10. Festas, I., Oliveira, A. L., Rebelo, J. A., Damião, M. H., Harris, K., \& Graham, S. (2015). Professional development in self-regulated strategy development: Effects on the writing performance of eighth grade Portuguese students. Contemporary Educational Psychology, 40, 17-27.

11. Fitzgerald, J. (2013). Struggling writers: Constructing their instruction: What and how. Annals of Dyslexia, 63, 80-95.

12. Flower, L. \& Hayes, J. R. (1981). A cognitive process theory of writing. College Composition and 
Communication, 32(4), 365-387.

13. Gao, W. Z. (2006). Analysis of Writing errors in sentences for elementary school students in Taiwan city (unpublished master's thesis). National Taichung University of Education, Taiwan.

14. Graham, S., \& Harris, K. (2003). Students with learning disabilities and the process of writing: A meta-analysis of RSD studies. In L. Swanson, K. Harris, \& S. Graham (Eds.), Handbook of research on learning disabilities (pp. 323-344). New York: Guilford Press.

15. Graham, S., \& Harris, K. R. (2009). Almost 30 years of writing research: Making sense of it all with the wrath of khan. Learning Disabilities Research \& Practice, 24, 58-68.

16. Graham, S., Harris, K. R., \& Mason, L. (2005). Improving the writing performance, knowledge, and motivation of struggling young writers: The effects of self-regulated strategy development. Contemporary Educational Psychology, 30, 207-241.

17. Graham, S., McKeown, D., Kiuhare, S., \& Harris, K. R. (2012). A meta-analysis of writing instruction for students in the elementary grades. Journal of Educational Psychology, 104, 879-896.

18. Harris, K. R., Graham, S., \& Adkins, M. (2015). Practice-based professional development and self-regulated strategy development for Tier 2, at-risk writers in second grade. Contemporary Educational Psychology, 40, 516.

19. Harris, K. R., Graham, S., \& Mason, L. H. (2006). Improving the writing, knowledge, and motivation of struggling young writers: Effects of self-regulated strategy development with and without peer support. American Educational Research Journal, 43, 295-340.

20. Harris, K., \& Graham, S. (1996). Making the writing process work: Strategies for composition and selfregulation $\left(2^{\text {nd }}\right.$ ed.). Cambridge, MA: Brookline Books.

21. Harris, K., \& Graham, S. (2009). Self-regulated strategy development in writing: Premises, evolution, and the future. British Journal of Educational Psychology, 6, 113-135.

22. Hayes, J. (1996). A new framework for understanding cognition and affect in writing. In M. Levy \& S. Ransdell (Eds.), The science of writing: Theories, methods, individual differences, and applications (pp. 1-27). Mahwah, NJ: Erlbaum.

23. Hayes, J. R., \& Flower, L. S. (1983). Uncovering cognitive processes in writing: An introduction to protocol analysis. In P. Mosenthal, L. Tamor, and S. Walmsley (Eds.), Research on writing: Principles and Methods (pp. 207-220). New York: Longman.

24. Hillocks, G. (1984). What works in teaching composition: A meta-analysis of experimental treatment studies. American Journal of Education, 93 (1), 133-170.

25. Jiang, M. Y. (2013). The study on writing development and teaching effectiveness of self-regulated learning strategy (unpublished Ph.D. dissertation). National Chen Kung University, Taiwan.

26. Mason, L. H., Harris, K. R., \& Graham, S. (2011). Self-regulated strategy development for students with writing difficulties. Theory Into Practice, 50, 20-27.

27. Millar, A., Simeone, R. S., \& Carnevale, J. T. (2001). Evaluation and Program Planning, 24(1), $73-81$.

28. Nakata, Y. (2010). Toward a framework for self-regulated. Language-Learning TESL Canada Journal, 27(2), 110 .

29. Psychological and Educational Testing Research and Development Center (2013). Criteria of writing test of basic academic competence for Junior high school students. Taipei, Taiwan: National Taiwan Normal University.

30. Reynolds, A. J. (1998). Confirmatory program evaluation: A method for strengthening causal inference. American Journal of Evaluation, 19(2), 203-221.

31. Santangelo, T., Harris, K. R. \& Graham, S. (2008). Using self-regulated strategy development to support students who have trouble getting things into words. Remedial and Special Education, 29 (2), 78-89.

32. Schunk, D. H. (2001). Social cognitive theory and self-regulated learning. In B. J. Zimmerman, \& D. H. Schunk $\left(2^{\text {nd }}\right.$ eds.), Self-regulated learning and academic achievement: Theoretical perspectives (pp. 125-151). Mahwah, NJ: Lawrence Erlbaum Associates Publishers.

33. Skibbe, L. E., Connor, C. M., Morrison, F. J., Jewkes, A. M. (2011). Schooling effects on preschoolers' selfregulation, early literacy, and language growth. Early Child Res Q. 26(1), 42-49.

34. Wang, Y. P. (2009). A comparison study of self-regulated strategy development writing teaching and concept mapping writing teaching to improve the writing of self-regulation, writing performance, and writing motivation for sixth graders (unpublished master's thesis). National Pingtung University of Education, Pingtung, Taiwan.

35. Xu, Y. H., \& Yang, S. H. (2010). Detection and analysis on the fourth graders' narrative writing skills in central Taiwan. Education Records, 23, 37-82. 
36. Yang, R. X. (2006). Sampling analysis of elementary schoolers' Grammar errors. In K. F. Wang \& L. G. Chen (eds.). Theory and practice of Chinese Writing. Taipei, Taiwan: Psychology Publication.

37. Zimmerman, B. J. (1986). Development of self-regulated learning: Which are the key sub-process. Contemporary Educational Psychology, 16, 307-313.

38. Zimmerman, B. J. (1989). Models of self-regulated learning and academic achievement. In B. J. Zimmerman \& D. H. Schunk (Eds.), Self-regulated learning and academic achievement: Theory, research, and practice (pp.125). New York: Springer-Verlag.

39. Zimmerman, B. J. (1998). Developing self-fulfilling cycles of academic regulation: An analysis of exemplary instructional models. In D. H. Schunk \& B. J. Zimmerman (Eds.), Self-regulated learning: From teaching to self-reflective practice (pp. 1-19). New York: The Guilford Press.

40. Zimmerman, B. J. (2001). Theories of self-regulated learning and academic achievement: an overview and analysis. In B. J. Zimmerman, \& D. H. Schunk (Eds.), Self-regulated learning and academic achievement: theoretical perspectives ( $2^{\text {nd }}$ ed.) (pp.2-37). Mahwah, NJ: Erlbaum. 